ANTONIO PRATELLI, M.S. ${ }^{1}$

(Corresponding author)

E-mail: antonio.pratelli@ing.unipi.it

PAOLO SECHI, M.S. ${ }^{1}$

E-mail: paosechi@gmail.com

REGINALD R. SOULEYRETTE, Ph.D. ${ }^{2}$

E-mail: souleyrette@uky.edu

1 University of Pisa,

Department of Civil and Industrial Engineering

Largo Lucio Lazzarino 2, 56122 Pisa, Italy

2 University of Kentucky, Department of Civil Engineering

Oliver H. Raymond Civil Engineering Building 161A,

40506 Lexington - KY, U.S.A.
Safety and Security in Traffic

Preliminary Communication

Submitted: 18 May 2017

Accepted: 28 Nov. 2017

\title{
UPGRADING TRAFFIC CIRCLES TO MODERN ROUNDABOUTS TO IMPROVE SAFETY AND EFFICIENCY - CASE STUDIES FROM ITALY
}

\begin{abstract}
This paper presents a procedure for analysing safety and operational improvements made possible by converting traffic circles to modern roundabouts. An Italian case study is presented for alternative layouts under various traffic demand scenarios. In the application of the procedure, the average waiting times and queue lengths at entries are computed with an analytical capacity model, using default values for gap parameters. Then, the roundabout is dynamically simulated. The simulation results in a revised set of gap parameters that are in turn used as inputs to a second trial of the capacity model, and in turn fed back into the simulation. The two steps are repeated until the parameters reach a pre-selected convergence criterion, so that gap parameter values for both the static capacity and dynamic microsimulation models are in equilibrium. Therefore, the applied procedure can conduct both static and dynamic roundabout design, usually applied separately. One can start with default values in guidelines and couple them with limited field data, improving both the expected results and cost-effectiveness of solutions. Next, safety is estimated using dynamic simulation software and a compatible conflict counting model to acquire surrogate measures of safety. Level-of-service and surrogate safety indicators for the existing and redesigned roundabouts are then compared. The procedure is first demonstrated on an old "ultra-large" roundabout. The procedure is tested on this roundabout using the Highway Capacity Manual 2016 (HCM2016), Aimsun ${ }^{T M}$, and Surrogate Safety Assessment Model (SSAM) software. A redesign is shown to be far superior in efficiency and safety. Finally, two cases are described where large first generation roundabouts were upgraded to modern standards.
\end{abstract}

\section{KEY WORDS}

traffic circles; modern multilane roundabout capacity models; multilane roundabouts design; operational efficiency analysis; traffic flow simulation;

\section{INTRODUCTION}

The modern roundabout was first introduced widely in the United Kingdom in the 1960s. Since then, it has become an increasingly popular alternative to traditional roadway stop, yield, and signal-controlled intersections. Although modern roundabout design is becoming the standard in many urban areas around the world, the public may confuse them with older style traffic circles and rotaries. The modern roundabout differs in critical ways from traffic circles and rotaries, and it is important to understand the history and evolution of the roundabout to illustrate these differences.

Following the Turner classification [1], traffic circles, which appeared at the beginning of the twentieth century, are designed for high-speed travel and generally feature large radii and high vehicle capacity. The general concept is that large radii provide long weaving sections in which high speeds and capacities can be attained. The design is intended for vehicle speeds not lower than $40 \mathrm{~km} / \mathrm{h}$ (25 mph) and requires a central island radius of at least $23 \mathrm{~m}(75 \mathrm{ft})$ so that entering vehicles can merge and interweave with those on the circulating roadway. The highest design speed contemplated is $64 \mathrm{~km} / \mathrm{h}$ (40 mph), a speed that requires a central island radius of $82 \mathrm{~m}(270 \mathrm{ft})$ or more, depending on the superelevation of the circulating roadway [2]. Some examples of traffic circles are Place De Gaulle in Paris (France), Grosser Stern in Berlin (Germany), Finsbury Circus in London (UK), Columbus Circle in New York City and Dupont Circle in Washington DC (USA).

A rotary is as an intersection where all traffic merges into and emerges from a one-way road that circumnavigates a central island [3]. Unlike the traffic circle, where roads generally intersect the circle at 
ninety-degree angles, the rotary creates merging lanes, allowing high-speed entry, and assigns priority to entering vehicles. High speeds are required because priority is given to the entering flow, reducing the need for entering vehicles to slow down and not to occupy the roundabout more than necessary: this priority rule is the main feature of the rotary, also known as the first generation roundabout.

Modern roundabouts, also known as second generation roundabouts, were introduced in the UK in 1966 and became popular worldwide in the 1990s. They shifted the priority rule, conferring priority to circulating flow rather than the entering flow. The new design was intended to reduce speed, and consequently, large radii are not needed or desired. Lower space requirements result in lower construction costs and greater safety due to the lower speeds [4].

The California Department of Transportation converted a traffic circle in Long Beach to a modern roundabout in 1993. This conversion was the first of its kind in the US and involved modifications to all entries. Included in the changes were the addition of greater entry deflection, yield signs, "YIELD AHEAD" signs, yield lines, and "YIELD" legends. After this conversion, total crash rate and injury crash rate declined sharply. Delays fell significantly, eliminating long queues that occurred regularly [5].

The modern roundabout is thus a more desirable solution for roadway intersections. But this raises a question: what should be done with older, less safe, traffic circles, rotaries, and first generation roundabouts?

Previous research from several countries has clearly shown that a properly designed roundabout can significantly improve traffic efficiency and road safety [6, $7,8,9]$.

Therefore, full reconstruction of traffic circle or rotaries into modern roundabouts is an option, but this may not be cost-effective. Upgrading rather than rebuilding these facilities is more feasible $[10,11]$. This paper suggests that many of the principal, distinguishing characteristics (and benefits) of the modern roundabout can be achieved or nearly achieved by making relatively minor changes to earlier designs.

Converting and upgrading traffic circles and rotaries to modern roundabouts is highly recommended to improve safety and functional performances of intersections. The following section of this paper presents an applied technical procedure to analyse traffic efficiency and safety conditions of roundabout design alternatives. The procedure first combines static and dynamic methods to determine entry capacity and operational performance. It then uses SSAM software to obtain surrogate safety indicators of proposed redesigns.

\section{THE COMBINED STATIC/DYNAMIC ANALYSIS PROCEDURE}

\subsection{Case study roundabout}

The following procedure has been tested on an old traffic circle, today operating as ultra-large roundabout, at the junction of Viale Boccaccio, Viale Nazario Sauro and Via di Levante, in Livorno, Italy (Figure 1).

This roundabout was selected because it was built as a traffic circle, about four decades ago. But since 1993, when the New Italian Highway Code introduced the rule of priority-to-circle, the circle has functioned as a modern roundabout simply due to changes in its yield signs. Therefore, the roundabout retains all the geometric properties of its original design. The main geometry elements are:

- very large diameter (104 m);

- three circulating lanes, each $3.75 \mathrm{~m}$ wide (so, inner ring has a $11.75 \mathrm{~m}$ width);

- three entry legs, with two 3.50 m lanes each (entry total width: $7 \mathrm{~m}$ );

- three exit legs, with the same characteristics as entry legs (two $3.50 \mathrm{~m}$ lanes each).

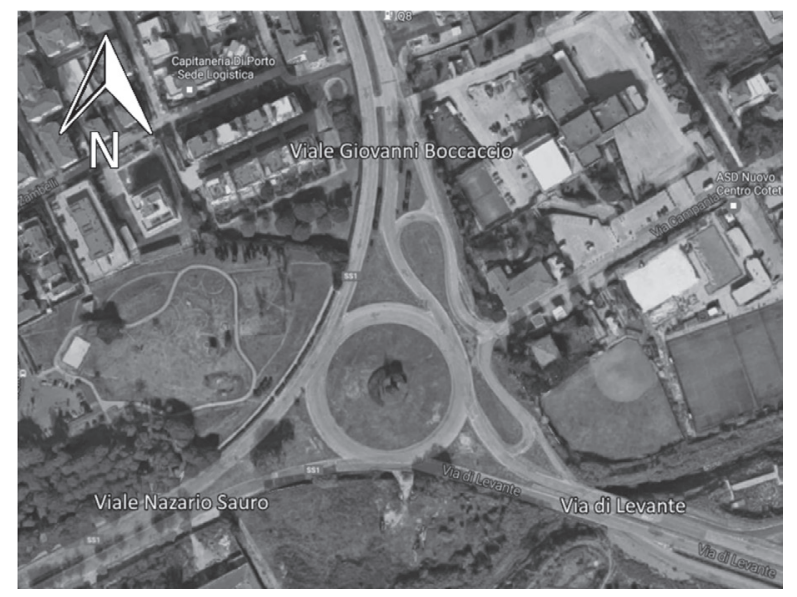

Figure 1 - Ultra-large roundabout in Livorno

A real dataset was used for model calibration and validation process. Traffic data were collected during a field survey performed by a camera recording AM peak hour flows (from 7:45 to 8:45) on selected weekdays in December 2015 on Livorno roundabout. An O/D matrix was derived from the observed data (Table 1 ).

Due to the roundabout's suburban location, there are no pedestrian flows and bicycle traffic is negligible.

Table 1 - Livorno O/D matrix from field survey [pc/h]

\begin{tabular}{|c|c|c|c|c||}
\hline & $\mathrm{N}$ & $\mathrm{SW}$ & $\mathrm{SE}$ & Total \\
\hline \hline $\mathrm{N}$ & 0 & 390 & 517 & 907 \\
\hline $\mathrm{SW}$ & 443 & 0 & 691 & 1,134 \\
\hline $\mathrm{SE}$ & 476 & 541 & 0 & 1,017 \\
\hline Total & 920 & 931 & 1,207 & 3,058 \\
\hline
\end{tabular}




\subsection{Methodology}

Theoretical models for determining roundabout capacity under mixed-traffic conditions are strongly affected by values of the parameters belonging to gap-acceptance theory. Manuals and technical guidelines usually suggest sets of parameter default values, assumed on nationwide datasets. Nevertheless, local calibration of capacity models is recommended to best reflect local driver behaviour [12]. Unfortunately, this calibration step on local field data is often neglected due to the significant time and resources needed to collect the necessary information $[7,13]$.

Therefore, the following procedure (Figure 2) was applied to perform the capacity analysis, starting from the default parameter values for the capacity models reported in national guidelines. Then, by an iterative

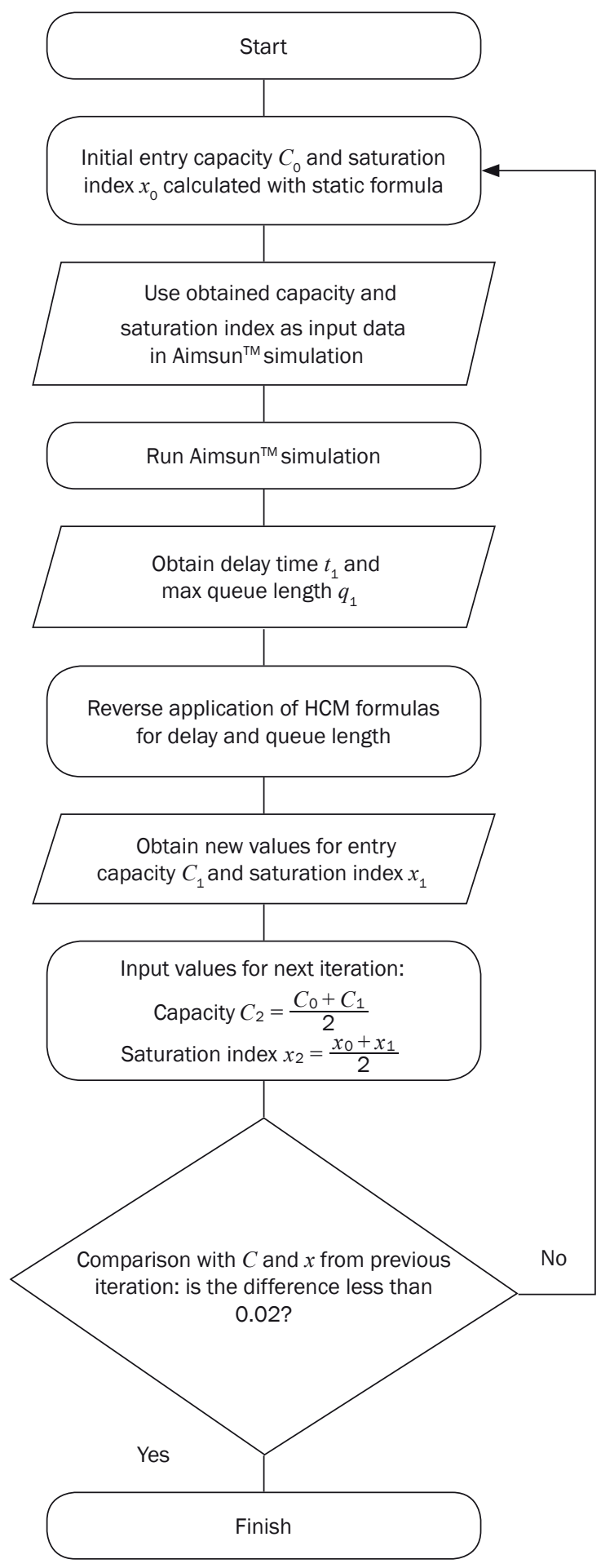

Figure 2 - Convergence algorithm flowchart 
process, parameter values were modified by a microsimulation step based on a few locally observed traffic data points. This way, one can improve the capacity analysis empirically, with small efforts in terms of field data collection and computational tools.

The Livorno roundabout has three lanes in the circulating carriageway. For this type of roundabout, the Federal Highway Administration (FHWA) proposes the use of specific capacity formulas [14], herein reported as 1 and 2:

$$
\begin{aligned}
& C_{e L}=e^{\left(7.1281-\frac{1.2403 \cdot c 1}{1,000}-\frac{1.2669 \cdot c 2}{1,000}-\frac{0.9709 \cdot c 3}{1,000}\right)} \\
& C_{e R}=e^{\left(7.1281-\frac{0.9838 \cdot c 1}{1,000}-\frac{1.0496 \cdot c 2}{1,000}-\frac{1.0352 \cdot c 3}{1,000}+0.7441 \cdot R_{t}\right)}
\end{aligned}
$$

where:

$C_{e L} \quad$ - left lane capacity [pc/h];

$C_{e R} \quad$ - right lane capacity [pc/h];

$c_{1}, c_{2}, c_{3}$-circulating flows in inner lane, middle lane and outer lane [pc/h], respectively;

$R_{t} \quad$ - ratio of right turning vehicles to total entering flow in the desired entry approach.

The formulas above were used for static analysis of the roundabout. For dynamic analysis, a model of the roundabout has been built (Figure 3) and calibrated using the simulation software Aimsun ${ }^{\mathrm{TM}}$ (Transport Simulation System (TSS))

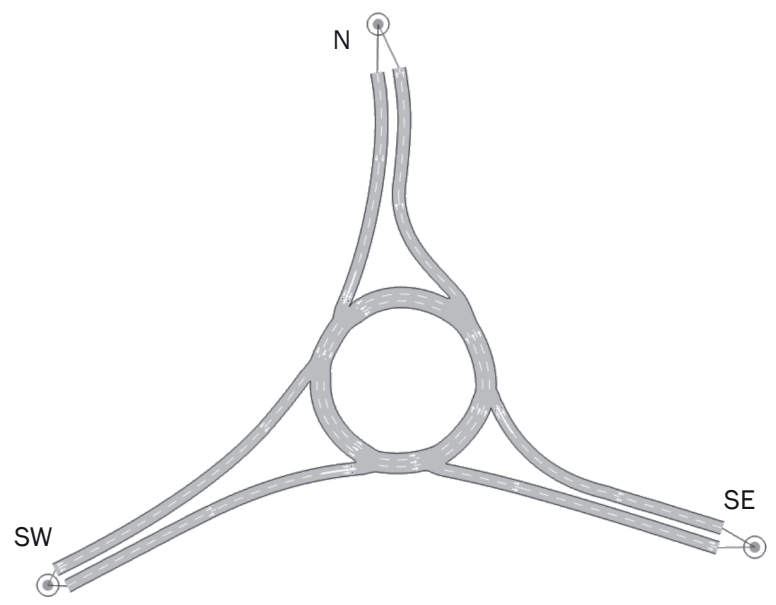

Figure 3 - Livorno three lanes roundabout model on Aimsun $^{\text {TM }}$

\subsection{Calibration of the model}

The delay time and $95^{\circ}$ percentile queue length were used as calibration and validation parameters. They are calculated using the Highway Capacity Manual 2016 (HCM2016) Formulas 3 and 4:

$$
\begin{aligned}
d= & \frac{3,600}{c}+ \\
& +900 T\left[x-1+\sqrt{(x-1)^{2}+\frac{\left(\frac{3,600}{c}\right) x}{450 T}}\right]+ \\
& +5 \min [x, 1]
\end{aligned}
$$

$Q_{95}=900 T\left[x-1+\sqrt{(x-1)^{2}+\frac{\left(\frac{3,600}{c}\right) x}{150 T}}\right]+\left(\frac{c}{3,600}\right)(4)$

where:

$d$ - delay time at entry $[\mathrm{s} / \mathrm{pc}]$;

$Q_{95}-95^{\circ}$ percentile queue length [pc];

$C$ - capacity at entry [pc/h];

$X$-saturation index (Entry flow/Entry capacity);

$T$ - period of reference ( $T$ is 0.25 for 15 minutes

traffic analysis, and 1 for 1 hour analysis)

Using 1 and 2 for capacity estimation, and assuming a distribution of flows in the circulating lanes of $10 \%$ the entry flow in the inner circulating lane, $65 \%$ in the middle lane, $25 \%$ in the outer lane, and calculating $R_{t}$ for each entry lane, the delay and queue length were estimated. The distribution flows in $\mathrm{pc} / \mathrm{h}$ and $R_{t}$ are shown in Table 2.

Table 2 - Circulating flows $[\mathrm{pc} / \mathrm{h}]$ and $R_{t}$ coefficient values

\begin{tabular}{|l|c|c|c||}
\hline \hline From - To & $c_{1}$ (inner) & $c_{2}$ (middle) & $c_{3}$ (outer) \\
\hline \hline N-SE & 55 & 340 & 121 \\
\hline SW-N & 47 & 292 & 104 \\
\hline SE-SW & 57 & 356 & 127 \\
\hline
\end{tabular}

\begin{tabular}{|l|c|c|c||}
\hline \hline Entry & $\mathrm{N}$ & $\mathrm{SW}$ & $\mathrm{SE}$ \\
\hline$R_{t}$ & 0.43 & 0.61 & 0.47 \\
\hline
\end{tabular}

The same O/D matrix shown in Table 1 was used in Aimsun $^{\mathrm{TM}}$ simulations to obtain the delay and queue length. Three indices measured goodness of fit:

- Root mean square percentile error (RMSPE)

$$
R M S P E=\sqrt{\frac{1}{n} \cdot \sum_{i=1}^{n}\left(\frac{x_{i}-y_{i}}{y_{i}}\right)^{2}}
$$

- Pearson's linear correlation coefficient $(r)$

$$
r=\frac{1}{n-1} \sum_{i=1}^{n} \frac{\left(x_{i}-\bar{x}\right)\left(y_{i}-\bar{y}\right)}{\sqrt{\sum_{i=1}^{n}\left(x_{i}-\bar{x}\right)^{2}} \sqrt{\sum_{i=1}^{n}\left(y_{i}-\bar{y}\right)^{2}}}
$$

- Theil's inequality coefficient $(U)$

$$
U=\frac{\sqrt{\frac{1}{n} \sum_{i=1}^{n}\left(y_{i}-x_{i}\right)^{2}}}{\sqrt{\frac{1}{n} \sum_{i=1}^{n} y_{i}^{2}} \sqrt{\frac{1}{n} \sum_{i=1}^{n} x_{i}^{2}}}
$$

The model was calibrated and validated when indices meet these conditions: $R M S P E<0.20, r>0.80$, $U<0.30$.

To calibrate and validate the simulation, the delays and queues from 3 and 4 were used as observed parameters, and output delays and queues from Aimsun $^{\mathrm{TM}}$ as simulated values. 
By setting the calibration parameters appropriately, the obtained measures of goodness of fit are presented in Table 3.

Table 3 - Calibration and validation results

\begin{tabular}{||c|c|c|c||}
\hline \hline & $\begin{array}{c}\text { Delay } \\
{[\mathrm{s}]}\end{array}$ & $\begin{array}{c}\text { Left queue } \\
{[\mathrm{pc}]}\end{array}$ & $\begin{array}{c}\text { Right queue } \\
{[\mathrm{pc}]}\end{array}$ \\
\hline \hline RMSPE & 0.09 & 0.14 & 0.19 \\
\hline$U$ & 0.96 & 0.95 & 0.99 \\
\hline$U$ & 0.04 & 0.06 & 0.08 \\
\hline
\end{tabular}

For queues, two decimals were considered for the better evaluation of the calibration process.

\subsection{Combined iterative procedure}

A combined iterative procedure (CIP) results from using the static formula and dynamic simulation as per following algorithm (see Figure 2): First, the capacity and saturation indices of entries were computed using the FHWA formulas applying default values for gap parameters. Next, these values were used as input to the simulation model. At the end of simulation, outputs were obtained to include the average delays, $d_{1}$, and queue length, $q_{1}$ at each entry. After simulation, the reported delays and queue values were used in a reverse application of the HCM2016 Formulas 3 and 4 for the delay and queue length calculation. This has produced new values of $C$ and $x$. The next step was to calculate the average values between the revised $C$ and $x$ and their previous values as follows:

Capacity $C_{2}=\frac{C_{0}+C_{1}}{2}$

Saturation index $x_{2}=\frac{x_{0}+x_{1}}{2}$

where:

$C_{0}, x_{0}$-capacity and saturation indices from the previous iteration (or starting values in the first iteration);

$C_{1}, x_{1}$-capacity and saturation index obtained with reverse application of HCM 2016 formulas during the current iteration

$C_{2}, x_{2}-$ mean values of capacity and saturation indices.

$C_{2}$ and $x_{2}$ were compared with $C$ and $x$ from the previous iteration (with $C_{0}$ and $x_{0}$ in case of the first iteration). If the difference between them was less than 0.02 , the iteration process stopped; if not, $C_{2}$ and $x_{2}$ were used as initial values for a new cycle.

Experimentally it has been observed that convergence takes place within a few cycles. The flowchart depicted in Figure 2 maps this iterative process, which is the core of CIP.

When the comparison test is satisfied, the capacity value obtained from the last iteration is used in reverse application of the static formula for capacity to recalculate its coefficients. In this case, a new value of the exponential coefficient, 7.1281 (from now on called $\alpha$ ) in the FHWA formula, was recalculated for the left and right lanes.

This process was applied for twelve alternative scenarios, obtaining thirteen values for $\alpha$ for each entry, more than enough for statistical significance. All coefficients of variation of $\alpha$ for all lanes were below 0.1 (the highest being 0.0885). An average value was calculated from these values of $\alpha$, so a new formulation may be written as:

$$
\begin{aligned}
& C_{e L}=e^{\left(7.1764-\frac{1.2403 \cdot c 1}{1,000}-\frac{1.2669 \cdot c 2}{1,000}-\frac{0.9709 \cdot c 3}{1,000}\right)} \\
& C_{e R}=e^{\left(6.7990-\frac{0.9838 \cdot c 1}{1,000}-\frac{1.0496 \cdot c 2}{1,000}-\frac{1.0352 \cdot c 3)}{1,000}+0.7441 \cdot R_{t}\right)}
\end{aligned}
$$

\section{COMBINED ITERATIVE PROCEDURE APPLIED TO A DIFFERENT DESIGN}

A new design is proposed for the ultra-large roundabout; one that eliminates the inner circulating lane while widening the two remaining circulating lanes from $3.75 \mathrm{~m}$ to $4.75 \mathrm{~m}$. The new design maintains the original diameter of $104 \mathrm{~m}$, the same radii at entries and exits, and features the following properties:

- same large diameter as the actual design (104 m);

- two circulating lanes, each 4.75 m wide (i.e., inner ring width: $9.5 \mathrm{~m}$ )

- three entry legs, with two 3.50 m lanes each (entry total width: $7 \mathrm{~m}$ )

- three exit legs, with the same characteristics as entry legs (two $3.50 \mathrm{~m}$ lanes each)

The roundabout could now be analysed as a twolane circulating roadway. An appropriate entry capacity formula for this kind of a roundabout is the HCM2016 general capacity formula [12], shown in 9.

$C_{e}=A \cdot e^{-B \cdot Q c}$

in which $A=\frac{3,600}{t_{f}}, B=\frac{t_{c}-\left(\frac{t_{f}}{2}\right)}{3,600}$

where:

$t_{c}$-critical headway [s];

$t_{f}$-follow-up time [s];

$Q_{c}$-total circulating flow $[\mathrm{pc} / \mathrm{h}]$.

A recent research study [10] suggests, for North Tuscany, the baseline values for $t_{c}$ and $t_{f}$ reported in Table 4.

Table 4 - North Tuscany baseline values for $t_{c}$ and $t_{f}$

\begin{tabular}{|l|c|c||}
\hline & $t_{c}[\mathrm{~s}]$ & $t_{f}[\mathrm{~s}]$ \\
\hline Left lane & 3.85 & 2.59 \\
\hline Right lane & 3.64 & 2.63 \\
\hline
\end{tabular}

Using the values in Table 4, the general Formula 9 changes to: 
Pratelli A, Sechi P, Souleyrett RR. Upgrading Traffic Circles to Modern Roundabouts to Improve Safety and Efficiency - Case Studies from...

$$
\begin{aligned}
& C_{e L}=1,390 \cdot e^{\left(-0.710 \cdot 10^{-3}\right) Q c} \\
& C_{e R}=1,369 \cdot e^{\left(-0.646 \cdot 10^{-3}\right) Q c}
\end{aligned}
$$

where:

$C_{e R}$-left lane capacity $[\mathrm{pc} / \mathrm{h}]$

$C_{e L}$-right lane capacity $[\mathrm{pc} / \mathrm{h}]$.

The new roundabout design was modelled in Aimsun $^{\mathrm{TM}}$, see Figure 4.

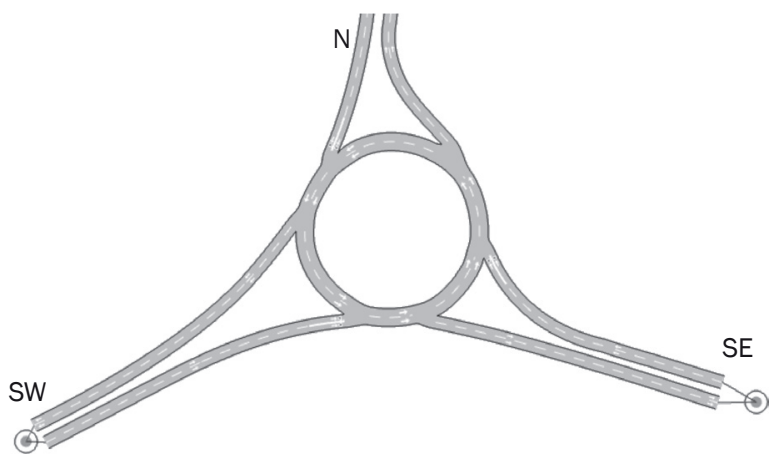

Figure 4 - Two-lane roundabout design model on Aimsun ${ }^{T M}$

For the calibration process, the O/D matrix in Table 1 was increased by $33 \%$ to simulate a greater traffic demand. The model was then calibrated and validated.

The CIP was then applied. After fulfilling the convergence criterion, capacity was obtained using the reverse application of 9 . Coefficients $A$ and $B$ were first recalculated, followed by $t_{c}$ and $t_{f}$

Table 6 - Static values and simulation output
Table 5 - Augmented O/D matrix used in HCM 2016 calibration

\begin{tabular}{||c|c|c|c|c||}
\hline & $\mathrm{N}$ & $\mathrm{SW}$ & $\mathrm{SE}$ & Total \\
\hline \hline $\mathrm{N}$ & 0 & 520 & 641 & 1,161 \\
\hline $\mathrm{SW}$ & 591 & 0 & 833 & 1,424 \\
\hline $\mathrm{SE}$ & 635 & 721 & 0 & 1,356 \\
\hline Total & 1,226 & 1,241 & 1,474 & 3,941 \\
\hline
\end{tabular}

The first iteration step of the CIP is presented in detail.

Using O/D matrix in Table 5, Formulas 10, 11, 3 and 4 were used to estimate capacity, delay, and queue for each entry lane.

Capacity and saturation index for every entry were used in Aimsun ${ }^{\mathrm{TM}}$ model (previously calibrated and validated). The program runs the simulation and gives delays and queues as output.

From Aimsun ${ }^{\mathrm{TM}}$ output, with reversal application of 3 and 4, new values for capacity and saturation index were calculated; Table 6 reports the results.

Finally, the average values between the starting values of $C$ and $x$ and the corresponding values from reversal application were calculated using 5 and 6 .

$\mathrm{N}$ entry $C_{2}=\frac{1,692+1,993}{2}=1,842 \mathrm{veh} / \mathrm{h}$;

$$
x_{2}=\frac{0.69+0.58}{2}=0.63
$$

\begin{tabular}{|c|c|c|c|c|c|c|}
\hline \multirow[t]{2}{*}{ Entry } & \multicolumn{2}{|c|}{$\mathrm{N}$} & \multicolumn{2}{|c|}{ SE } & \multicolumn{2}{|c|}{ SW } \\
\hline & Left & Right & Left & Right & Left & Right \\
\hline$Q_{e}[\mathrm{pc} / \mathrm{h}]$ & 615 & 546 & 755 & 669 & 719 & 637 \\
\hline \multirow{2}{*}{ Capacity $C$ [pc/h] } & 833 & 859 & 882 & 905 & 914 & 934 \\
\hline & \multicolumn{2}{|c|}{1,692} & \multicolumn{2}{|c|}{1,787} & \multicolumn{2}{|c|}{1,848} \\
\hline \multirow{2}{*}{ Saturation index $x$} & 0.73 & 0.64 & 0.86 & 0.74 & 0.79 & 0.68 \\
\hline & \multicolumn{2}{|c|}{0.69} & \multicolumn{2}{|c|}{0.80} & \multicolumn{2}{|c|}{0.73} \\
\hline \multicolumn{7}{|c|}{ Initial values from static formulas } \\
\hline Delay [s/pc] & 19.92 & 14.58 & 30.68 & 18.71 & 21.85 & 15.43 \\
\hline$Q_{95}[\mathrm{pc}]$ & 7.90 & 5.06 & 14.49 & 7.98 & 10.01 & 6.38 \\
\hline \multicolumn{7}{|c|}{ Output from Aimsun ${ }^{\mathrm{TM}}$} \\
\hline Delay $[\mathrm{s} / \mathrm{pc}]$ & 18.09 & 14.41 & 29.42 & 20.00 & 16.49 & 12.47 \\
\hline$Q_{95}[\mathrm{pc}]$ & 7.77 & 6.58 & 11.11 & 9.73 & 8.11 & 5.67 \\
\hline \multicolumn{7}{|c|}{ Values of $C$ and $x$ from reversal application of 3 and 4} \\
\hline \multirow{2}{*}{ Capacity $C[\mathrm{pc} / \mathrm{h}]$} & 922 & 1,070 & 719 & 989 & 1,071 & 1,148 \\
\hline & \multicolumn{2}{|c|}{1,993} & \multicolumn{2}{|c|}{1,708} & \multicolumn{2}{|c|}{2,220} \\
\hline \multirow{2}{*}{ Saturation index $x$} & 0.73 & 0.70 & 0.81 & 0.78 & 0.74 & 0.64 \\
\hline & \multicolumn{2}{|c|}{0.58} & \multicolumn{2}{|c|}{0.83} & \multicolumn{2}{|c|}{0.61} \\
\hline
\end{tabular}

SE entry $C_{2}=\frac{1,787+1,708}{2}=1,748$ veh $/ \mathrm{h}$;

$$
x_{2}=\frac{0.80+0.83}{2}=0.82
$$


SW entry $C_{2}=\frac{1,848+2,220}{2}=2,034 \mathrm{veh} / \mathrm{h}$

$$
x_{2}=\frac{0.73+0.61}{2}=0.67
$$

These values were used as starting values for the second iteration step. The procedure continues until the convergence criterion is satisfied.

The entire process was repeated for twelve alternative scenarios, obtaining thirteen values of $t_{c}$ and $t_{f}$ for each entry lane.

All coefficients of variation for $t_{c}$ were less than 0.1 (the highest being 0.0958). For $t_{f}$, all coefficients of variation were less than 0.3 (the highest being 0.2896 ). As before, the average values were calculated and new Formulas 12 and 13 written with newly obtained values of $t_{c}, t_{f}, A$, and $B$.

Table 7 - CIP obtained values of $t_{c}$ and $t_{f}$

\begin{tabular}{||l|l|l||}
\hline \multicolumn{1}{|c|}{ CIP } & $t_{c}[\mathrm{~s}]$ & $t_{f}[\mathrm{~s}]$ \\
\hline \hline Left lane & 3.93 & 2.74 \\
\hline Right lane & 3.46 & 2.27 \\
\hline
\end{tabular}

$$
\begin{aligned}
& C_{e L}=1,312 \cdot e^{\left(-0.71 \cdot 10^{-3}\right) Q c} \\
& C_{e R}=1,588 \cdot e^{\left(-0.646 \cdot 10^{-3}\right) Q c}
\end{aligned}
$$

\section{PERFORMANCE COMPARISON}

Original and CIP-modified Level of Service (LOS) merit comparison. Using the HCM2016 methodology, LOS was determined as a function of delay times, as follows:

\begin{tabular}{c|cc}
\hline $\begin{array}{c}\text { Control Delay } \\
\text { (s/veh) }\end{array}$ & \multicolumn{2}{c}{ LOS by Volume-to-Capacity Ratio } \\
\hline $0-10$ & v/c $\mathbf{1 . 0}$ & v/c $>\mathbf{1 . 0}$ \\
\hline $010-15$ & $\mathrm{~A}$ & $\mathrm{~F}$ \\
$>15-25$ & $\mathrm{~B}$ & $\mathrm{~F}$ \\
$>25-35$ & $\mathrm{C}$ & $\mathrm{F}$ \\
$>35-50$ & $\mathrm{D}$ & $\mathrm{F}$ \\
$>50$ & $\mathrm{E}$ & $\mathrm{F}$ \\
\hline
\end{tabular}

Figure 5 - Level of Service determination criterion (from HCM2016)

To compare the original FHWA formula and the original HCM formula to the respective CIP versions, the O/D matrix in Table 8 was used. This matrix was the only $\mathrm{O} / \mathrm{D}$ matrix used as alternative scenario in both FHWA and HCM cases.

Table 8 - O/D matrix used in comparison $[\mathrm{pc} / \mathrm{h}]$

\begin{tabular}{|c|c|c|c|c||}
\hline & $\mathrm{N}$ & $\mathrm{SW}$ & $\mathrm{SE}$ & Total \\
\hline \hline $\mathrm{N}$ & 0 & 387 & 491 & 878 \\
\hline $\mathrm{SW}$ & 521 & 0 & 612 & 1,133 \\
\hline $\mathrm{SE}$ & 479 & 608 & 0 & 1,087 \\
\hline
\end{tabular}

In the FHWA-CIP comparison, the following values were used for circulating flows (in $\mathrm{pc} / \mathrm{h}$ ), and turning ratio.

Table 9 - FHWA circulating flows and turning ratio

\begin{tabular}{||c|c|c|c||}
\hline & $c_{1}$ & $c_{2}$ & $c_{3}$ \\
\hline \hline $\mathrm{N}$ & 142 & 401 & 64 \\
\hline $\mathrm{SW}$ & 115 & 324 & 52 \\
\hline $\mathrm{SE}$ & 122 & 344 & 55 \\
\hline \multicolumn{4}{|c||}{ Turning Ratio } \\
\hline & $\mathrm{N}$ & $\mathrm{SW}$ & $\mathrm{SE}$ \\
\hline$R_{t}$ & 0.44 & 0.54 & 0.44 \\
\hline
\end{tabular}

Using the data above, entry capacities were calculated first with FHWA Formulas 1 and 2, then with CIP-modified Formulas 7 and 8. Capacity $C_{e}$ is expressed in $\mathrm{pc} / \mathrm{h}$.

Table 10 - Capacity values for each entry lane in FHWA- CIP comparison

\begin{tabular}{||c|c|c|c||}
\hline \hline Entry & Lane & $C_{e}$ (FHWA $)$ & $C_{e}$ (CIP) \\
\hline \hline \multirow{2}{*}{$N$} & Left & 590 & 619 \\
\cline { 2 - 4 } & Right & 855 & 615 \\
\hline \multirow{2}{*}{ SW } & Left & 681 & 715 \\
\cline { 2 - 4 } & Right & 1,021 & 735 \\
\hline \multirow{2}{*}{ SE } & Left & 657 & 689 \\
\cline { 2 - 4 } & Right & 935 & 673 \\
\hline
\end{tabular}

Delays for each lane were calculated with 3. Entry lane flows were calculated according to HCM2016 general prescription; therefore, $53 \%$ of the total entry flow was assigned to the left lane, with the remaining $47 \%$ assigned to the right one. The obtained values are presented in Table 11.

Table 11 - Entry flows distribution between left and right lane

\begin{tabular}{|c|c|c||}
\hline & $v_{l}[\mathrm{pc} / \mathrm{h}]$ & $v_{r}[\mathrm{pc} / \mathrm{h}]$ \\
\hline \hline $\mathrm{N}$ & 465 & 413 \\
\hline $\mathrm{SW}$ & 600 & 533 \\
\hline $\mathrm{SE}$ & 576 & 511 \\
\hline
\end{tabular}

Where $v_{l}$ and $v_{r}$ are flows on the left entry lane and right entry lane, respectively. The flows were then divided by capacities to find the entry lane saturation index.

Approach delay was calculated with the HCM2016 Formula 14:

$d_{\text {approach }}=\frac{d_{l} \cdot v_{l}+d_{r} \cdot v_{r}}{v_{l}+v_{r}}$

where:

$d_{l}, d_{r}$-delays for the left and right lanes;

$v l, v_{r}$-entry flows for the left and right lanes. 
Pratelli A, Sechi P, Souleyrett RR. Upgrading Traffic Circles to Modern Roundabouts to Improve Safety and Efficiency - Case Studies from...

Table 12 - FHWA- CIP comparison

\begin{tabular}{||c|c|c|c|c|c|c|c|c||}
\hline \hline \multicolumn{2}{||c|}{ Delay [s] } & \multicolumn{2}{c||}{ LOS } \\
\cline { 2 - 9 } & FHWA & CIP & FHWA & CIP & FHWA & CIP & FHWA & CIP \\
\hline \hline N & 31.61 & 26.52 & 10.54 & 20.90 & 21.70 & 23.88 & C & C \\
\hline SW & 43.57 & 33.57 & 9.96 & 21.11 & 27.77 & 27.72 & D & D \\
\hline SE & 43.86 & 33.99 & 11.19 & 25.40 & 28.51 & 29.95 & D & D \\
\hline
\end{tabular}

Table 12 provides the comparison results. As can be seen, LOS is the same for both cases.

A similar comparison was made between the results using the HCM2016 capacity formula and the CIP-modified version. The O/D matrix from the previous case (see Table 8) was again used. Circulating flows for all entries were $608 \mathrm{pc} / \mathrm{h}$ for the North entry, $491 \mathrm{pc} / \mathrm{h}$ for the South-West entry and $521 \mathrm{pc} / \mathrm{h}$ for the South-East entry. The capacities were calculated with 10 and 11 for HCM2016, and with 12 and 13 for CIP Capacities are expressed in $\mathrm{pc} / \mathrm{h}$.

Table 13 - Capacity values for each entry lane in HCM CIP comparison

\begin{tabular}{||c|c|c|c||}
\hline Entry & Lane & $C_{e}$ (FHWA $)$ & $C_{e}$ (CIP) \\
\hline \hline \multirow{2}{*}{$\mathrm{N}$} & Left & 903 & 853 \\
\cline { 2 - 4 } & Right & 924 & 1,071 \\
\hline \multirow{2}{*}{ SW } & Left & 981 & 927 \\
\cline { 2 - 4 } & Right & 997 & 1,155 \\
\hline \multirow{2}{*}{ SE } & Left & 960 & 907 \\
\cline { 2 - 4 } & Right & 978 & 1,133 \\
\hline
\end{tabular}

Due to the O/D matrix being the same as the previous case, even the entry flow distribution on each lane was the same as observed previously (see Table 11).

Again, saturation indices were calculated, followed by delays in the left lane, right lane, and on approach. Lastly, LOS was evaluated. The results are reported in Table 14.
The slight difference in delays between the HCM2016 and CIP calculations was sufficient for LOS change in the North entry (to LOS B to LOS A).

\section{SURROGATE SAFETY ANALYSIS}

Due to large radii and high speeds, the safety of ultra-large roundabouts is usually poor. To evaluate the safety performance of different designs for the Livorno roundabout, Surrogate Safety Assessment Model (SSAM) software was used. SSAM was developed by the FHWA as an alternative tool for crash analysis and analysing and calculating conflict points based on vehicle trajectories. It is necessary first to simulate the roundabout with a program such as Aimsun ${ }^{\mathrm{TM}}$, Vis$\operatorname{sim}^{\mathrm{TM}}$, or Paramics ${ }^{\mathrm{TM}}$ and extract trajectory data in a .trj file. These binary files contain, for every simulation step, the position and the speed of each vehicle in the simulation.

SSAM incorporates the .trj files, and uses each vehicle's trajectory to identify conflicts. It reports the results in tabular or graphical format [15]. SSAM's operative flow is shown in Figure 6.

SSAM classifies conflict types based on angle $\theta$ between two vehicle's trajectories, as shown in Figure 7. If $\theta$ is between $0^{\circ}$ and $20^{\circ}$, the trajectories are aligned and both vehicles are assumed to be in the same lane and travelling in the same direction. Such conflicts are classified as Rear End Conflicts.

Table 14 - HCM 2016 - CIP comparison

\begin{tabular}{|c|c|c|c|c|c|c|c|c|}
\hline \multicolumn{7}{|c|}{ Delay [s] } & \multirow{2}{*}{\multicolumn{2}{|c|}{ LOS }} \\
\hline & \multicolumn{2}{|c|}{ Left lane } & \multicolumn{2}{|c|}{ Right lane } & \multicolumn{2}{|c|}{ Approach } & & \\
\hline & HCM 2016 & CIP & HCM 2016 & CIP & HCM 2016 & CIP & HCM 2016 & CIP \\
\hline $\mathrm{N}$ & 10.79 & 11.99 & 9.26 & 7.39 & 10.07 & 9.83 & B & A \\
\hline SW & 12.47 & 14.20 & 10.40 & 8.08 & 11.50 & 11.32 & B & $B$ \\
\hline SE & 12.33 & 13.98 & 10.31 & 8.04 & 11.38 & 11.19 & B & B \\
\hline
\end{tabular}

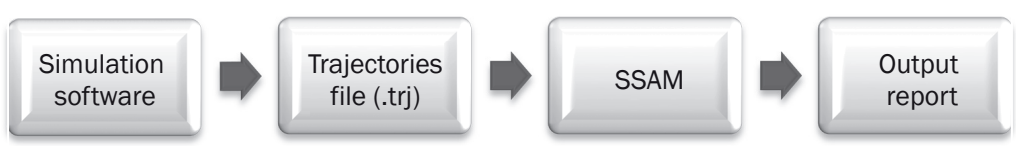

Figure 6 - SSAM operative flow 


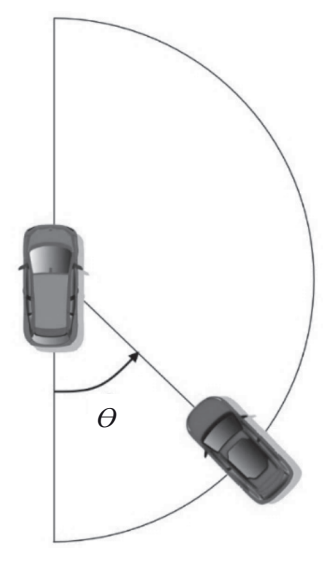

Figure 7 - Angle $\theta$ for conflicts classification

If $\theta$ is between $20^{\circ}$ and $85^{\circ}$, the vehicles are assumed to be in different lanes, with one vehicle encroaching. Such conflicts are classified as Lane Changing Conflicts.

If $\theta$ is between $85^{\circ}$ and $180^{\circ}$, one vehicle is assumed to be crossing into the lane of the other, either perpendicularly to or from the opposite direction. These are classified as Crossing Conflicts, and they are usually considered to be far more severe than other conflict types.

To evaluate the safety of alternative designs, a comparison between the current Livorno Roundabout and three alternatives was made. The roundabout's current design (Design A) has three circulating lanes and a diameter of 104 metres (see Figure 3).

The second design (Design B; Figure 4), is a variant of the first, but with two circulating lanes.

The third design (Design C; Figure 8) has two circulating lanes and a diameter of $54 \mathrm{~m}$, which is 47 percent less than the current diameter.

The fourth design (Design D; Figure 9), is a variant of Design $C$, in which two bypass lanes are added: one for the North to South-West direction, and one for the South-West to South-East direction.

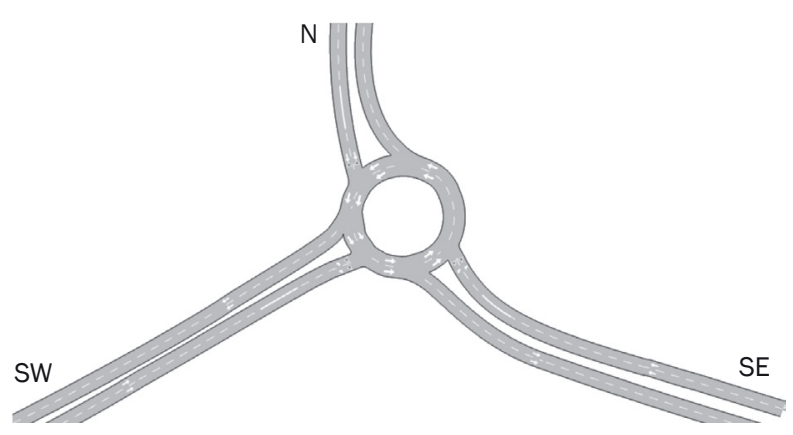

Figure 8 - Design C: 54 metres diameter

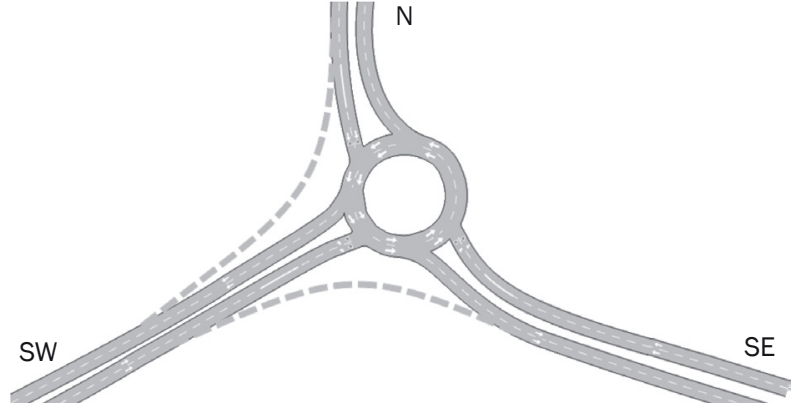

Figure 9 - Design D: 54 metres diameter with bypass

All designs were modelled using Aimsun ${ }^{\mathrm{TM}}$ and simulated using the same parameters and under the same conditions (i.e., simulation steps, reaction times, O/D matrix in Table 8).

Trajectory files were extracted following the simulation runs and analysed in SSAM. The results are shown for times to collision (TTC) of $1.5 \mathrm{~s}$ and $1.0 \mathrm{~s}$.

The results indicated that Design $D$ offers the best safety performance: conflicts are approximately half of the level expected with other designs (Table 15).

Table 15 - Conflicts output from SSAM elaboration

\begin{tabular}{||c|c|c|c|c||}
\hline \multicolumn{5}{|c|}{ TTC 1.5 s } \\
\hline Design & Crossing & $\begin{array}{c}\text { Lane } \\
\text { Changing }\end{array}$ & $\begin{array}{c}\text { Rear } \\
\text { end }\end{array}$ & Total \\
\hline \hline A & 0 & 386 & 54 & 440 \\
\hline B & 0 & 365 & 65 & 430 \\
\hline C & 1 & 366 & 115 & 481 \\
\hline D & 1 & 184 & 66 & 250 \\
\hline \hline \multicolumn{5}{|c|}{ TTC 1.0 s } \\
\hline Design & Crossing & $\begin{array}{c}\text { Lane } \\
\text { changing }\end{array}$ & $\begin{array}{c}\text { Rear } \\
\text { end }\end{array}$ & Total \\
\hline \hline A & 0 & 181 & 29 & 210 \\
\hline B & 0 & 151 & 32 & 183 \\
\hline C & 0 & 165 & 63 & 228 \\
\hline D & 0 & 86 & 34 & 120 \\
\hline
\end{tabular}

\section{COMPARING LEVEL OF SERVICE}

Comparing the LOS among the four designs highlights interesting differences. Previously, in section 4, delays and LOS were calculated and compared using original and CIP-modified formulas. Using the same O/D matrix presented in section 4 (Table 8 ) and the CIP formulas, delays and LOS of Designs $C$ and $D$ were estimated. Comparisons of the four designs are reported in Table 16.

As with safety, Design D offers the best functional performance. It may therefore be concluded that reducing radii and constructing bypasses in the free space (where and when possible) increase the operating efficiency safety of the ultra-large roundabout. 
Pratelli A, Sechi P, Souleyrett RR. Upgrading Traffic Circles to Modern Roundabouts to Improve Safety and Efficiency - Case Studies from...

Table 16 - LOS comparison of the four designs

\begin{tabular}{|c|c|c|c|c|c|}
\hline \multirow{2}{*}{ Design } & \multirow{2}{*}{ Entry } & \multicolumn{3}{|c|}{ Delay [s] } & \multirow{2}{*}{ LOS } \\
\hline & & Left lane & Right lane & Approach & \\
\hline \multirow{3}{*}{ A } & $\mathrm{N}$ & 26.52 & 20.90 & 23.88 & $\mathrm{C}$ \\
\hline & SW & 33.57 & 21.11 & 27.72 & $\mathrm{D}$ \\
\hline & SE & 33.99 & 25.40 & 29.95 & $\mathrm{D}$ \\
\hline \multirow{3}{*}{ B } & $\mathrm{N}$ & 11.99 & 7.39 & 9.83 & A \\
\hline & SW & 14.20 & 8.08 & 11.32 & $B$ \\
\hline & SE & 13.98 & 8.04 & 11.19 & B \\
\hline \multirow{3}{*}{$C$} & $\mathrm{~N}$ & 11.99 & 7.39 & 9.83 & $A$ \\
\hline & SW & 14.20 & 8.08 & 11.32 & $B$ \\
\hline & SE & 13.98 & 8.04 & 11.19 & $B$ \\
\hline \multirow{3}{*}{$D$} & $\mathrm{~N}$ & 7.77 & 5.45 & 6.68 & $A$ \\
\hline & SW & 7.25 & 5.14 & 6.26 & A \\
\hline & SE & 13.98 & 8.04 & 11.19 & $B$ \\
\hline
\end{tabular}

\section{TWO CASES BEFORE AND AFTER: SESTO FIORENTINO AND LUCCA}

It has been proposed and demonstrated that upgrading old roundabouts can be an effective way to increase the operating and safety performance. To further substantiate this claim, two real-world cases are presented.

The first case is a circle traffic roundabout in Sesto Fiorentino [15], near Florence. This roundabout has the following characteristics:

- 54 m inscribed circle diameter;

- 26m central island diameter;

- two circulating lanes, each $3.8 \mathrm{~m}$ wide (so, the inner ring has a $7.6 \mathrm{~m}$ width);

- four single lane entry legs, with different lane widths (NW entry width $3.85 \mathrm{~m}$; NE entry width $6.20 \mathrm{~m}$; SW entry width $5.20 \mathrm{~m}$; SE entry width 5.85 $\mathrm{m})$;

- four exit legs, with different lane widths (NW exit width $4.20 \mathrm{~m}$; NE exit lane width $6.15 \mathrm{~m}$; SW exit width $5.20 \mathrm{~m}$; SE entry width $5.85 \mathrm{~m}$ ).

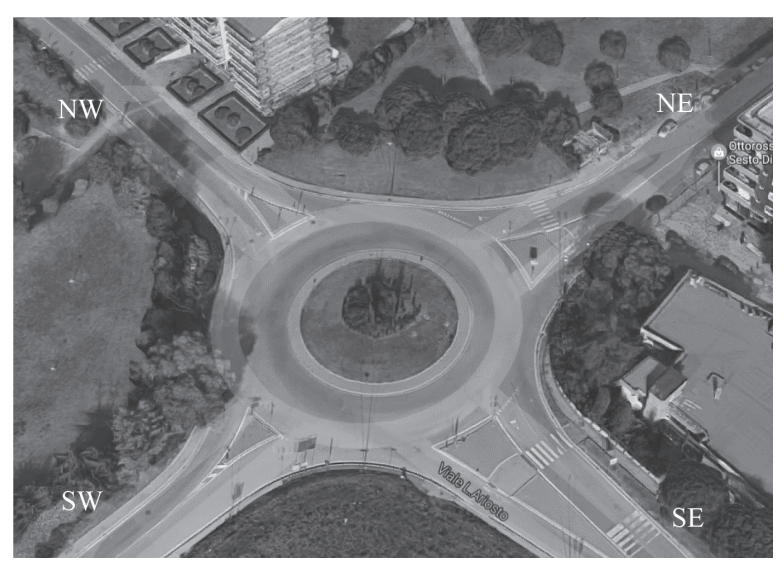

Figure 10 - Sesto Fiorentino roundabout after upgrade
The roundabout was converted to modern roundabout status by modifying its road signs. However, it retained its original geometry.

In 2004, the roundabout was redesigned with these changes to original dimensions:

- 13 m central island diameter;

- two circulating lanes, each $6.3 \mathrm{~m}$ wide (so, the inner ring has a $12.6 \mathrm{~m}$ width);

- two lanes for each entry.

The new geometry increased LOS for each approach, with two approaches increasing from LOS F to LOS A. On average, queue lengths decreased to $1 / 3$ of their initial values. Anecdotally, safety performance has also increased significantly. The delays, queue length, and LOS values before and after the redesign are reported in Table 17.

A second example of improved general performance afforded by redesign is a roundabout in Lucca, an historic city in Tuscany [16]. There, an ultra-large

Table 17 - Sesto Fiorentino roundabout performances before and after the redesign

\begin{tabular}{|c|c|c|c||}
\hline \multicolumn{4}{|c||}{ Sesto Fiorentino roundabout before redesign } \\
\hline Entry & $\begin{array}{c}\text { Delay } \\
{[\mathrm{s}]}\end{array}$ & $\begin{array}{c}\text { Queue } \\
\text { length }[\mathrm{m}]\end{array}$ & LOS \\
\hline \hline NW & 51 & $>180$ & $\mathrm{~F}$ \\
\hline $\mathrm{NE}$ & 6 & 12 & $\mathrm{~A}$ \\
\hline SW & $>60$ & $>180$ & $\mathrm{~F}$ \\
\hline SE & 42 & 84 & $\mathrm{E}$ \\
\hline \hline \multicolumn{4}{|c|}{ Sesto Fiorentino roundabout after redesign } \\
\hline Entry & $\begin{array}{c}\text { Delay } \\
{[\mathrm{s}]}\end{array}$ & $\begin{array}{c}\text { Queue } \\
\text { length [m] }\end{array}$ & LOS \\
\hline \hline NW & 2.5 & 12 & $\mathrm{~A}$ \\
\hline NE & 2 & 6 & $\mathrm{~A}$ \\
\hline SW & 2 & 12 & $\mathrm{~A}$ \\
\hline SE & 2.5 & 12 & $\mathrm{~A}$ \\
\hline
\end{tabular}


roundabout with a diameter of $85 \mathrm{~m}$ was located just outside one of the old gateways to the city of Porta Santa Maria. The roundabout had four approaches ( $\mathrm{N}$, $\mathrm{E}, \mathrm{S}, \mathrm{W})$ and three exits. Its central island had a diameter of $78 \mathrm{~m}$, and the circulating carriageway was $6 \mathrm{~m}$ wide.

It had two circulating lanes, but the presence of trucks and buses in peak hours made one lane unavailable for cars.

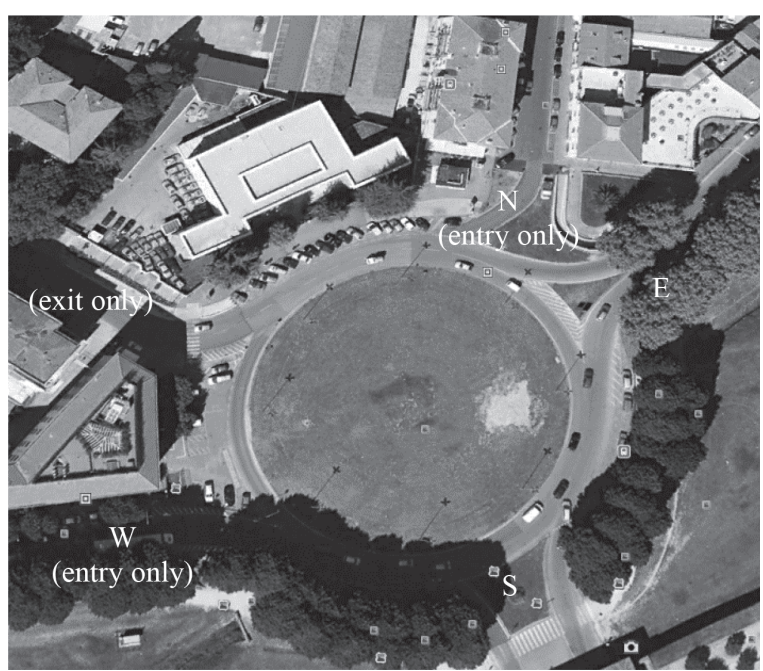

Figure 11- Lucca roundabout before upgrade

In 2010 the roundabout was upgraded to a new design: its diameter was reduced to $55 \mathrm{~m}$ and the circulating lanes were enlarged to $4.75 \mathrm{~m}$, widening its carriageway to $9.5 \mathrm{~m}$ (plus 2 metres of mountable apron).

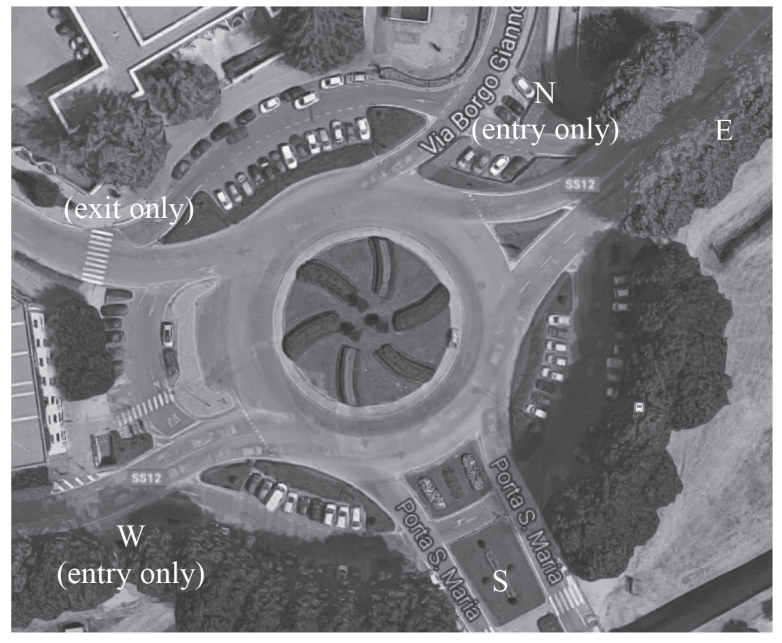

Figure 12 - Lucca roundabout after upgrade

This new design reduced delays and queue length, increased safety, and established better performance. As shown in Table 18, with its original design, the Lucca roundabout offered very poor performance; after relatively inexpensive upgrades, the operations and safety improved significantly. As an added benefit, which may extend to other locations, the space created by reducing the roundabout may be made available for other uses. At the Lucca roundabout, the newly created space was used to install 80 parking spaces, generating more than enough income to pay for the upgrades.

Table 18 - Lucca roundabout performances before and after redesign

\begin{tabular}{|c|c|c|c||}
\hline \multicolumn{5}{|c||}{ Lucca roundabout before redesign } \\
\hline Entry & Delay [s] & $\begin{array}{c}\text { Queue } \\
\text { length [m] }\end{array}$ & LOS \\
\hline \hline $\mathrm{N}$ & $>60$ & $>30$ & $\mathrm{~F}$ \\
\hline $\mathrm{W}$ & $>60$ & $>30$ & $\mathrm{~F}$ \\
\hline $\mathrm{S}$ & $>60$ & $>30$ & $\mathrm{~F}$ \\
\hline $\mathrm{E}$ & $>60$ & $>30$ & $\mathrm{~F}$ \\
\hline \hline \multicolumn{4}{|c|}{ Lucca roundabout after redesign } \\
\hline Entry & Delay [s] & $\begin{array}{c}\text { Queue } \\
\text { length [m] }\end{array}$ & LOS \\
\hline \hline N & 8 & 9 & A \\
\hline W & 20 & $>30$ & C \\
\hline S & 14 & 8 & B \\
\hline E & 32 & 29 & D \\
\hline \hline
\end{tabular}

\section{CONCLUSIONS}

This paper has discussed the practicalities and the benefits of upgrading large, older generation traffic circles or rotaries. This issue is of growing interest, especially in Italy where today a number of old rotaries are still operating without modification. Upgrading of the traffic circle or rotaries to modern roundabouts is often required for tasks of traffic efficiency and road safety.

Studies of roundabouts in various countries have shown that proper design and modelling can significantly improve traffic efficiency and road safety $[6,7$, 8, 9].

The characteristics of modern roundabouts can be achieved by making new design and changes. Such changes are related to geometry and are addressed to introduce modern roundabout guidelines for outer radius, sight distance, number and lane width, weaving length recommendations, entrance and exit width, splitter islands, and flare lengths.

A simple method for calibrating analytical tools and assessing the benefits was also applied. By iterative use of static capacity models and dynamic simulations, one can reach better results using limited resources in terms of field data and computational difficulty.

The last obtained solution through microsimulation gives the trajectory files. These last ones are used as input to perform the safety analysis applying SSAM software. 
Computational tests were performed on an existing old traffic circle in the city of Livorno, comparing its performance to three alternative upgraded designs. For each of the latter ones, the obtained results lead to a general confirmation of all initial expectations.

Nevertheless, there are small differences between results obtained through the applied procedure and those derived from the static formula. These differences can be explained by the input being a set of local parameters values especially calibrated for North Tuscany. It could arguably have been expected to measure larger differences if the chosen input set had been the one referred to in the US calibrated parameters of HCM2016 default values.

The paper also discussed the case studies in Italy, where old, very large traffic circles were converted into modern roundabouts. Today, these operate at a better level of service and safety.

Even if the obtained results are encouraging, they are limited to one instance. Therefore, future research should work to validate the procedure applied in this paper using other examples of converting old traffic circles to modern roundabout standards.

\section{Prof. ANTONIO PRATELLI ${ }^{1}$}

E-mail: antonio.pratelli@ing.unipi.it

Dr. PAOLO SECHI ${ }^{1}$

E-mail: paosechi@gmail.com

Prof. REGINALD R. SOULEYRETTE ${ }^{2}$

E-mail: souleyrette@uky.edu

1 Università di Pisa,

Dipartimento di Ingegneria civile e industriale

Largo Lucio Lazzarino 2, 56122 Pisa, Italia

2 University of Kentucky, Department of Civil Engineering Oliver H. Raymond Civil Engineering Building 161A, 40506 Lexington - KY, U.S.A.

\section{ADATTARE LE ROTONDE IN MODERNE ROTATORIE PER INCREMENTARE LA SICUREZZA E L'EFFICIENZA - CASI DI STUDIO IN ITALIA}

\section{SINTESI}

L'articolo descrive una procedura iterativa originale messa a punto per analizzare i miglioramenti funzionali e di sicurezza ottenibili convertendo le rotonde in rotatorie moderne, o di seconda generazione. Viene portato ad esempio un caso di studio italiano in cui si analizzano differenti geometrie per diversi scenari di traffico. La procedura inizia con il calcolo dei tempi medi di attesa e la lunghezza delle code alle entrate, che sono stimati con un modello analitico della capacità usando i valori di default per i parametri degli intervalli. Quindi si esegue una prima simulazione dinamica della rotatoria. Dalla simulazione si ottiene un set corretto di valori dei parametri per l'intervallo critico e per quello di susseguimento. Questo set corretto viene utilizzato come input per una nuova stima con il modello analitico della capacità, i cui risultati vengono utilizzati in un secondo ciclo di simulazione. Queste due fasi vengono ripetute fino a quando i valori dei parametri non soddisfano il criterio di con- vergenza stabilito, ovvero in modo che i valori dei parametri degli intervalli critico e di susseguimento siano in equilibrio sia nel modello statico di capacità, sia nel modello dinamico di simulazione. In questo modo la procedura permette la progettazione della rotatoria in modo dinamico e statico contemporaneamente, mentre invece di solito i due metodi sono applicati separatamente, o l'uno o l'altro. La procedura proposta può partire dai valori suggeriti dalla manualistica e combinarli con pochi dati sperimentali presi sul campo, a tutto vantaggio sia dei risultati attesi, sia della riduzione dei costi di progettazione. Successivamente, la sicurezza viene stimata usando un programma di simulazione dinamica e un modello di calcolo dei conflitti tra le manovre compatibili, in modo da acquisire misure di sicurezza surrogata, infine i livelli di servizio e gli indici di sicurezza surrogata per la rotatoria esistente e per le sue geometrie alternative vengono messi a confronto. La procedura è stata testata su una vecchia rotonda "ultra-large" di prima generazione, usando le formule dell'Highway Capacity Manual 2016, il software di simulazione Aimsun ${ }^{T M}$, e il programma Surrogate Safety Assessment Model (SSAM). Una delle alternative esaminate si mostra molto migliore in termini di efficienza e sicurezza. Al termine vengono descritti due casi di rotatorie di prima generazione adattate agli standard delle rotatorie moderne.

\section{PAROLE CHIAVE}

rotonde; modelli di capacità per rotatorie a più corsie nell'anello; analisi di progetto e funzionalità operative di rotatorie a più corsie nell'anello; simulazione dei flussi di traffico;

\section{REFERENCES}

[1] Turner D. Roundabouts: a literature review. weblog, 2011. Available from: http://www.danielrturner.com/ home/wp-content/uploads/2012/12/Roundabouts. pdf [Accessed 29th November2017].

[2] K. Todd. A History of Roundabouts in the United States and France. Transportation Quarterly. 1988;42(4): 599-623.

[3] Taekratok T. Modern roundabouts for Oregon. Oregon Department of Transportation. Rep. n.98-SRS-522, Salem; 1998.

[4] Tollazzi T. Alternative Types of Roundabouts- An Informational Guide. New York: Springer; 2015.

[5] Gates TJ, Maki RE. Converting Old Circles to Modern Roundabouts: Michigan State University Case Study. In: Proceedings of ITE 2000 Annual Meeting and Exhibit. Nashville, Tennessee; 2000.

[6] Legac I, Pilko H, Brcic D. Analysis of traffic capacity and design for the reconstruction of large roundabout in the city of Zagreb. In: Pratelli A. (ed.) Intersection Control and Safety. Ashurst, U.K.: WIT Press; 2013. p. 17-28.

[7] Pilko H, Mandzuka S, Baric D. Urban single-lane roundabouts: A new analytical approach using multi-criteria and simultaneous multi-objective optimization of geometry design, efficiency and safety, Transportation Research Part C. 2017;80: 257-271.

[8] Vasconcelos A, Seco A, Silva A. Comparison of Procedures to Estimate Critical Headways at Roundabouts. Promet - Traffic \& Transportation. 2013;25(1): 43-53.

[9] Al-Madani HMN, Pratelli A. Modeling and calibrating 
capacity of large roundabouts. International Journal of Sustainable Development and Planning. 2014;9(1): 54-73.

[10] Gazzarri A, Martello MT, Pratelli A, Souleyrette RR. Estimation of gap acceptance parameters for HCM 2010 for roundabout capacity model applications. WIT Transactions on the Built Environment: Urban Transport XVIII. 2012;128: 309-320.

[11] Transportation Research Board. Highway Capacity Manual. 6th edition. Washington DC: National Research Council; 2016.

[12] Gagnon C, Sadek A, Touchette A. Calibration potential of common analytical and microsimulation roundabout models: New England case study. Transportation Research Record. 2008;2071: 77-86.

[13] Bared JG, Afshar AM. Using Simulation to Plan Capacity Models by Lane for Two- and Three-lane roundabouts. Transportation Research Record: Journal of the Transportation Research Board. 2009;2096: 8-15.

[14] Federal Highway Administration. Surrogate Safety As- sessment Model (SSAM) - User Manual. Federal Highway Administration. Rep. FHWA-HRT-08-050, Washington DC, 2008.

[15] Pratelli A, Margheri G. Studio di Fattibilità per Interventi sulla Rotatoria Querciola-Ariosto-Togliatti. Technical Report, Pisa, 2003.

[16] Suffredini E. Ristrutturazione della Rotatoria di Porta Santa Maria con Aumento dell'Accessibilità al Centro Storico di Lucca. BS thesis. Department of Civil Engineering of University of Pisa; 2008.

[17] Mauro R, Cattani M. Functional and economic evaluations for choosing road intersection layout. Promet Traffic \& Transportation. 2012;24(5): 441-448.

[18] Baric D, Pilko H, Strujic J. An analytic hierarchy process model to evaluate road section design. Transport 31 . 2016;(3): 312-321.

[19] Tollazzi T, Sram M, Lerher T. Roundabout arm capacity determined by microsimulation and discrete functions technique. Promet - Traffic \& Transportation. 2008;20(5): 291-300. 